\title{
Infertility analysis by hysterolaparoscopy
}

\author{
Archana V. Daddenavar ${ }^{1}$, Vikas M. Daddenavar ${ }^{2}$ \\ ${ }^{1}$ Department of Obstetrics and Gynaecology, S N Medical College, Bagalkot, Karnataka, India \\ ${ }^{2}$ Department of Surgery, S N Medical College, Bagalkot, Karnataka, India
}

Received: 04 March 2016

Revised: 10 March 2016

Accepted: 30 March 2016

*Correspondence:

Dr. Archana V. Daddenavar,

E-mail: drarchanavd@gmail.com

Copyright: (C) the author(s), publisher and licensee Medip Academy. This is an open-access article distributed under the terms of the Creative Commons Attribution Non-Commercial License, which permits unrestricted non-commercial use, distribution, and reproduction in any medium, provided the original work is properly cited.

\begin{abstract}
Background: Hysteroscopy provides a means of direct observation of intra-uterine defects, which can eventually interfere with fertility and as a therapy for intra-uterine lesions, for which hysteroscopy is the method of choice. To study the various etiological factors responsible for infertility in females by using hystero-laparoscopy.

Methods: Prospective study of patients admitted with diagnosis of infertility in Department of Obstetrics and Gynaecology in S N Medical College, Bagalkot from October 2013-April 2015.

Results: Of the 50 cases of infertility, 35 cases (70\%) were of primary infertility and 15 cases (30\%) were of secondary infertility. Most of the patients (74\%) had duration of Infertility of 1-5 years. Various etiological factors detected during study are uterine factors in $12 \%$, tubal factors in $34 \%$, ovarian factors in $18 \%$. Unexplained in $16 \%$ of cases.

Conclusions: In present study, hysterolaparoscopy helped in diagnosis of certain factors causing infertility which can't be diagnosed by any other method short of hysterolaparoscopy. Tubal factors were found to be major cause of infertility.
\end{abstract}

Keywords: Laparoscopy, Hysteroscopy, Infertility

\section{INTRODUCTION}

Experience has shown that pelvic abnormality in the infertile patient is frequently not appreciated by pelvic examination and the usual diagnostic studies. For this reason, direct endoscopic technique has been advanced as a routine component of the complete evaluation of the infertile woman. Hysteroscopy provides a means of direct observation of intra-uterine defects, which can eventually interfere with fertility and as a therapy for intra-uterine lesions, for which hysteroscopy is the method of choice. ${ }^{1}$ Laparoscopy often brings to light unexpected pelvic pathology. Early and subtle causes of infertility thus revealed and treated lead to rewarding results. Hysterolaparoscopy thus provides a comprehensive investigative procedure in which various factors causing female infertility can be assessed at one sitting.

\section{METHODS}

This is a prospective study of 50 cases of infertility, who reported to the outpatient Department of Obstetrics and Gynecology S N Medical College, Bagalkot from October 2013 to April 2015. Hysterolaparoscopy was done as a diagnostic aid in these patients. Some of the patients had already been subjected to few of the preliminary investigations. Only cases with no male factor involving infertility were taken for this study.

After completion of relevant investigations including Preanaesthetic check-up, the patients were put up for diagnostic hysterolaparoscopy. Patient was admitted a day prior to the operation. The hysterolaparoscopy was done in the post-ovulatory phase usually in the premenstrual time. Hysterolaparoscopy was performed 
under general anaesthesia and the patients were kept for a period of 24 hours in the hospital post-operatively.

\section{RESULTS}

The present study consisted of 50 cases of infertility who were evaluated by hysterolaparoscopy, during a period from October 2013 to April 2015. Of the 50 cases, 35 cases $(70 \%)$ were of primary infertility and 15 cases $(30 \%)$ were of secondary infertility.

Most of the patients of both primary and secondary infertility (74\%) had duration of infertility of 1-5years. Amongst the 15 cases of secondary infertility under study, the pregnancy immediately preceding the period of infertility terminated in abortion (spontaneous or induced) in $46.7 \%$ of the cases, and in a full term normal delivery in $33 \%$ of the cases.
Table 1 shows the abnormal hysteroscpoic findings in this study. Uterine anomalies included 2 cases of septate uterus and 1 case of bicornuate uterus. All the cases of intrauterine adhesions were of secondary infertility. In the present study laparoscopic findings showed that uterine factors were responsible for infertility in 6 cases $(12 \%)$ i.e. 4 cases $(11.43 \%)$ of primary infertility and 2 cases $(13.3 \%)$ of secondary infertility .Of primary infertility 1 case $(2.86 \%)$ was detected to have mullerian anomaly bicornuate uterus.

Table 1: Pathological findings on hysteroscopy.

\begin{tabular}{|lll|}
\hline Findings & No. of cases & $\%$ \\
\hline Uterine anomalies & 03 & $6 \%$ \\
\hline Intrauterine adhesions & 02 & $4 \%$ \\
\hline Submucous fibroids & 01 & $2 \%$ \\
\hline
\end{tabular}

Table 2: Abnormal tubal findings on laparoscopy.

\begin{tabular}{|ll|lllll|}
\hline Causes & $\begin{array}{l}\text { Primary no. } \\
\text { of cases }\end{array}$ & $\%$ & $\begin{array}{l}\text { Secondary no. of } \\
\text { cases }\end{array}$ & \multicolumn{2}{c|}{ Total } \\
no. of cases & \% \\
\hline Bilateral tubal block & 4 & 11.42 & 2 & 13.3 & 6 & 12 \\
\hline Unilateral tubal block & 2 & 5.72 & 3 & 20 & 5 & 10 \\
\hline Delayed spillage & 1 & 2.86 & - & - & 1 & 2 \\
\hline Peritubal adhesions & 2 & 6.72 & - & - & 2 & 4 \\
\hline Hydrosalpinx & 3 & 8.57 & - & - & 3 & 6 \\
\hline Total & 12 & 34.29 & 5 & 33.3 & 17 & 34 \\
\hline
\end{tabular}

Table 3: Abnormal ovarian findings on laparoscopy.

\begin{tabular}{|c|c|c|c|c|c|c|}
\hline Causes & $\begin{array}{l}\text { Primary no. } \\
\text { of cases }\end{array}$ & $\%$ & $\begin{array}{l}\text { Secondary no. of } \\
\text { cases }\end{array}$ & $\%$ & $\begin{array}{l}\text { Total } \\
\text { no. of cases }\end{array}$ & $\%$ \\
\hline PCOD & 4 & 11.43 & 1 & 6.66 & 5 & 10 \\
\hline Streak ovaries & 1 & 2.86 & - & - & 1 & 2.0 \\
\hline Ovarian cysts & 1 & 2.86 & 1 & 6.66 & 2 & 4.0 \\
\hline Paraovarian cysts & 1 & 2.86 & - & - & 1 & 2 \\
\hline Total & 7 & 20 & 2 & 13.32 & 9 & 18 \\
\hline
\end{tabular}

Table 4: Peritoneal factors in infertility.

\begin{tabular}{|c|c|c|c|c|c|c|}
\hline Causes & $\begin{array}{l}\text { Primary no. } \\
\text { of cases }\end{array}$ & $\%$ & $\begin{array}{l}\text { Secondary no. of } \\
\text { cases }\end{array}$ & $\%$ & $\begin{array}{l}\text { Total } \\
\text { no. of cases }\end{array}$ & $\%$ \\
\hline Endometriosis & 1 & 2.86 & - & - & 1 & 2 \\
\hline Pelvic adhesions & 3 & 8.57 & 2 & 13.3 & 5 & 10 \\
\hline Pelvic infection & 3 & 8.57 & 1 & 6.7 & 4 & 8 \\
\hline Total & 7 & 20 & 3 & 20 & 10 & 20 \\
\hline
\end{tabular}

A total of 4 cases $(8.0 \%)$ had bulky uterus with fibroids of which 2 cases $(5.71 \%)$ were of primary infertility and
2 cases $(13.3 \%)$ of secondary infertility. Endometrial tuberculosis was detected in 1 case of primary infertility. 
On the whole, uterine factors were responsible for $12.0 \%$ of cases of infertility.

Table 2 shows abnormal tubal findings on laparoscopy and were responsible for 12 cases $(34.29 \%)$ of primary infertility and 5 cases $(33.3 \%)$ of secondary infertility. Chromopertubation test using methylene blue dye, to assess the patency of the fallopian tubes, was done in all the 50 cases of the present study. Out of the total 50 cases, Chromopertubation test was bilaterally positive i.e. both the tubes were found to be patent in 36 cases of which 27 cases $(77.14 \%)$ were of primary infertility and 9 cases (60\%) were of secondary infertility. Chromopertubation test was not perceived in 2 cases (4\%) due to dense adhesions.

Table 5: Cause of infertility at laparoscopy.

\begin{tabular}{|ll|lllll|}
\hline Causes & $\begin{array}{l}\text { Primary no. } \\
\text { of cases }\end{array}$ & \% & $\begin{array}{l}\text { Secondary no. of } \\
\text { cases }\end{array}$ & \% & $\begin{array}{l}\text { Total } \\
\text { no. of cases }\end{array}$ & $\%$ \\
\hline Uterine factors & 4 & 11.43 & 2 & 13.3 & 6 & 12 \\
\hline Tubal factors & 12 & 34.29 & 5 & 33.3 & 17 & 34.0 \\
\hline Ovarian factors & 7 & 20.2 & 1 & 3.3 & 9 & 18.0 \\
\hline Peritoneal factors & 7 & 20 & 3 & 20 & 10 & 20.0 \\
\hline Unexplained & 5 & 14.28 & 3 & 20.0 & 8 & 16.0 \\
\hline Total & 35 & 100.2 & 14 & 89.9 & 50 & 100 \\
\hline
\end{tabular}

Table 3 shows various abnormal ovarian findings on laparoscopy. In the present study, ovarian factors as a cause of infertility were detected in a total of 9 cases - 7 cases $(20 \%)$ of primary infertility and 2 cases (13.32\%) of secondary infertility. Of the mentioned 2 cases of ovarian cysts, 1 case of serous cystadenoma and 1 case of chocolate cyst of the ovary (endometriosis) was detected. All the cases had unilateral cysts of the ovary.

As can be observed from Table 4 various peritoneal factors were seen in a total of 10 cases - 7 cases $(20 \%)$ of primary infertility and 3 cases (20\%) of secondary infertility. Pelvic endometriosis was detected in 1 case $(2.86 \%)$ of primary infertility. As already mentioned before, endometriosis in the form of chocolate cyst of the ovary was seen in 1 case. Therefore in the present study, the overall incidence of endometriosis was found to be $4 \%$ of all the infertility cases studied. Pelvic infection was detected in a total of 4 cases of which 3 cases $(8.57 \%)$ were of primary infertility and 1 case $(6.7 \%)$ was of secondary infertility. Pelvic adhesions as an isolated finding in the absence of any other factors were seen in a total of 5 cases $(10 \%)-3$ cases $(8.57 \%)$ of primary infertility and 2 cases (13.3\%) of secondary infertility. Hence, in the present study, peritoneal factors were found responsible for $20 \%$ of all the cases of infertility $-20 \%$ of primary infertility and $20 \%$ of secondary infertility.

As can be observed from Table 5, in the present series, uterine factors were detected in 4 cases $(11.43 \%)$ of primary infertility and in 2 cases $(13.3 \%)$ of secondary infertility. Tubal factors were detected in 12 cases $(34.29 \%)$ of primary infertility and 5 cases $(33.3 \%)$ of secondary infertility. Ovarian factors were found responsible in 7 cases $(20 \%)$ of primary infertility and 2 cases $(13.3 \%)$ of secondary infertility. Peritoneal factors were implicated in 7 cases $(20 \%)$ of primary infertility and 3 cases (20\%) of secondary infertility.

In many cases, there were more than one factors involved. The most severe, important and significant one was considered. Hence, as can be seen, some pelvic abnormality i.e. pelvic pathology was detected in $84.0 \%$ of the cases under study. Out of the 50 women in the present study, in 8 cases a thorough laparoscopic evaluation failed to reveal any cause. These women were labelled as cases of unexplained infertility and accounted for $16.0 \%$ of the infertile women undergoing laparoscopic evaluation.

\section{DISCUSSION}

In our study, Hysterolaparoscopy as "one time approach" was adopted after preliminary investigations of the couple. In the present study, the incidence of primary infertility was $70 \%$ and that of secondary infertility was $30 \%$ which correlates with the studies conducted by Templeton and Kerr primary infertility (74.9\%) and secondary infertility $(25.1 \%)$, Sharma $\mathrm{R}$ et al- primary infertility (67.2\%) and secondary infertility (32.8\%), Nakade KD et al - primary infertility (69.4\%) and secondary infertility $(30.6 \%))^{2-4}$ As in our study, in the study conducted by Sharma $\mathrm{R}$ et al, the pregnancy terminated immediately preceding the period of infertility with FTND in $32.4 \%$, with previous preterm delivery in $8.1 \%$, intrauterine foetal death in $8.1 \%$. $^{3}$ Majority of the patients of this particular study $-51.3 \%$ also gave history of previous abortions. Diagnostic Hysteroscopy revealed abnormality in only $12.33 \%$ cases. Other study reported in literature give incidence of intrauterine adhesions as 
$25 \%$ (Malhotra $\mathrm{N}$ et al), $23.4 \%$ (Keminiski $\mathrm{P}$ et al). ${ }^{5,6}$ In our study, intrauterine adhesions were detected in $4 \%$ cases and all these cases were of secondary infertility. In $2.66 \%$ cases the adhesions were quite fragile and flimsy. Sub mucus fibroid was seen in only one case i.e.1.33\%. Reported incidence in various studies varies from $9.4 \%$ (Malhotra $\mathrm{N}$ et al) and $14.3 \%$ (Keminski P et al). ${ }^{5,6}$ In the present study, uterine factors were responsible for infertility in 12 cases $-11.4 \%$ of primary infertility and $13.3 \%$ of secondary infertility which are comparable to $12 \%$ in studies conducted Nakade KD et al and $14 \%$ in Chakraborti et al. ${ }^{4,7}$ In the present study tubal factors were found responsible for the majority of cases $-34 \%$. These result are comparable with those of Chakraborti et al (39.0\%), Prabhu TRB et al $(31.5 \%)$ and Bhide AG et al $(42.9 \%){ }^{1,8,9}$ Fertility depends upon the presence of normal fallopian tubes with respect to patency, persistence and free fimbrial motion. Partial or complete occlusion of fallopian tubes is one of the major etiological factors in infertility. In addition, various pathologies like peritubal and periovarian adhesions etc. may also be responsible for causing infertility. In the present study tubal disease was diagnosed in $34.0 \%$ of the women and that is in keeping with results of other studies in which tubal disease was reported to account in total or in part for infertility in 25 to $50.0 \%$. This finding indicates that tubal dysfunction continues to be a major determinant to involuntary female infertility. In the present study, ovarian factors were implicated in $18 \%$ of the cases and in study by Bhide AG et al (9.7\%) had lower incidence. ${ }^{1}$ Comparatively in the present study, ovarian pathology found in laparoscopy is much higher In the present study, peritoneal factors were detected in $20 \%$ of cases, which is comparatively higher than the result of Bhide AG et al study (10.9\%). ${ }^{1}$ In 8 of the 50 women under study in the present series hysterolaparoscopy failed to reveal any abnormality. These women were labelled as cases of unexplained infertility and they accounted for $16.0 \%$ of the women undergoing laparoscopic evaluation in the present study. The incidence of unexplained infertility obtained by the present series is in accordance with the studies of others Chakraborti et al $(21.4 \%)^{7}$

\section{CONCLUSION}

Hysterolaparoscopy is a feasible and acceptable procedure. It can be used as "One Time Approach" in the assessment of female infertility. Hysterolaparoscopy as a diagnostic procedure may be considered essential in all cases of infertility. It gives maximum information, in respect of fertility status of women as compared to any other single procedure. It shortens the duration of investigation of infertile couple thereby relieving the anxiety of those who are found normal and enables early treatment of those who are suffering from treatable cause of infertility. Hysterolaparoscopy reveals whether surgery is possible and if so the nature of surgery most suited for the patient. This gives the surgeon an opportunity to be prepared for any eventuality during surgery.

\section{Funding: Not required}

Conflict of interest: None declared

Ethical approval: The study was approved by the Institutional Ethics Committee

\section{REFERENCES}

1. Bhide AG. Laproscopic evaluation of the etiopathology of infertility. Journal of Obstet and gynaecol of India. 1990;40:680-2.

2. Templeton AA and Kerr MG. An assessment of laparoscopy as the primary investigation in the subfertile female. Br J Obst Gynaecol. 1997;84:7602.

3. Sharma R, Taly A, Guleri AS. Laparoscopic evaluation of cases of primary and secondary infertility. J of Obst Gyn of India. 1997;47:366-71.

4. Nakade KD, Deokar SS. Comparative evaluation of laparoscopy and hysterosalpingography in infertility. J of Obst and Gyn of India. 1993;43:784-7.

5. Malhotra M, Sood M. Role of hysteroscopy in infertile women. J Indian Med Assoc. 1997;95:499525.

6. Keminski P, Wieczorek $\mathrm{K}$, Marianowski L. Usefulness of hysteroscopy in diagnosing sterility. Ginekol Pol. 1992;63:634-7.

7. Chakraborti DK, Kole SK. Diagnostic laparoscopy in gynaecologic disorders. J of Obst and Gyn of India. 1990;40:262-5.

8. Prabhu TRB, Sivaraman R, Srinivasan C, Rajarathnam S. Diagnostic laparoscopy A Review of 800 Cases. J of Obst Gyn of India. 1998;38:205-7.

Cite this article as: Daddenavar AV, Daddenavar VM. Infertility analysis by hysterolaparoscopy. Int J Reprod Contracept Obstet Gynecol 2016;5:1472-5. 